\title{
Immune Tolerance to Autoantibody-derived Peptides Delays Development of Autoimmunity in Murine Lupus
}

\author{
Ram Raj Singh, ${ }^{\star}{ }^{*}$ Fanny M. Ebling, ${ }^{\star}$ Eli E. Sercarz, ${ }^{\star}$ and Bevra H. Hahn* \\ Departments of $*^{*}$ Medicine/Rheumatology and ${ }^{\ddagger}$ Microbiology and Molecular Genetics, University of California, Los Angeles, \\ California 90095
}

\begin{abstract}
Mechanisms that initiate and maintain autoantibody (autoAb) production in individuals with autoimmune diseases like SLE are poorly understood. Inadequate suppression of autoreactive $T$ cells and/or unusual activation of $T$ and $B$ cells may underlie the persistence of pathogenic autoAbs in lupus. Here, we examine the possibility that in mice with lupus, autoAb molecules may be upregulating their own production by activating self-reactive $T$ cells via their own processed peptides; downregulation of this circuit may decrease autoAb production and delay the development of lupus. We found that before the onset of clinical disease, lupus-prone (NZB/NZW) F1 [BWF1] (but not MHCmatched nonautoimmune mice) developed spontaneous $T$ cell autoimmunity to peptides from variable regions of heavy chains $\left(V_{H}\right)$ of syngeneic anti-DNA mAbs but not to peptides from the $V_{H}$ region of an $m A b$ to an exogenous antigen. Tolerizing young BWF1 mice with intravenous injections of autoAb-derived determinants substantially delayed development of anti-DNA antibodies and nephritis and prolonged survival. Thus, in such an autoAb-mediated disease, the presence of autoreactive $T$ cells against $V_{H}$ region determinants of autoAbs may represent an important mechanism involved in the regulation of autoimmunity. Our findings show that tolerizing such autoreactive $T$ cells can postpone the development of an autoimmune disease like SLE. (J. Clin. Invest. 1995. 96:2990-2996.) Key words: antigenic determinants $\cdot$ autoantibodies $\cdot$ autoimmunity $\bullet$ systemic lupus erythematosus $\cdot T$ cells
\end{abstract}

\section{Introduction}

The persistence of autoreactive $\mathrm{T}$ and/or B lymphocytes in individuals with autoimmune diseases is an enigma. Autoanti-

This paper was presented in part at the Annual Meeting of the American College of Rheumatology in Minneapolis, MN on 23-27 October 1994 and has appeared in abstract form (1994. Arthritis \& Rheum. 37:221s).

Address correspondence to Ram Raj Singh, UCLA Department of Medicine/Rheumatology, 32-47 Rehabilitation Center, Box 951670, Los Angeles, CA 90095-1670. Phone: 310-825-7791; Fax: 310-2068606.

Received for publication 17 March 1995 and accepted in revised form 13 September 1995.

J. Clin. Invest.

(C) The American Society for Clinical Investigation, Inc.

$0021-9738 / 95 / 12 / 2990 / 07 \quad \$ 2.00$

Volume 96, December 1995, 2990-2996 body (autoAb)-mediated diseases such as SLE are interesting in this regard because $B$ cells secreting pathogenic autoreactive antibodies $(\mathrm{Ab})$ are supported by $\mathrm{T}$ helper $(\mathrm{Th})^{1}$ cells, implying defects in regulation of both types of cells $(1,2)$. Defective central or peripheral tolerance, inadequate suppression of autoreactive cells, and/or unusual activation of $T$ and $B$ cells may underlie the persistence of autoAbs that characterizes SLE.

(NZB/NZW) F1 [BWF1] mice, like some humans with SLE, develop spontaneous autoimmune disease characterized by persistent production of IgG Ab to DNA and glomerulonephritis caused at least in part by subsets of such $\mathrm{Ab}(2-5)$. IgG anti-DNA production is dependent on autoreactive $\mathrm{T}$ cell help (6-9). Since B cells are capable of processing their own Ig and presenting the resultant peptides to $\mathrm{T}$ cells via their MHC class II molecules (10-13), autoAb molecules might contain increased numbers of $T$ cell determinants which can be recognized by $\mathrm{T}$ cells from genetically predisposed autoimmune individuals. The activated $T$ cells would then provide help for continuing synthesis of those autoAbs. This possibility was explored by measuring the proliferative response of $\mathrm{T}$ cells from unimmunized young BWF1 and normal mice to peptides derived from the variable region of heavy chains $\left(V_{H}\right)$ of syngeneic IgG anti-DNA and to $V_{H}$ of an $A b$ to a foreign antigen $(\mathrm{Ag})$. The in vivo importance of the $\mathrm{T}-\mathrm{B}$ interactions was tested by measuring the effect of immune tolerance to autoAbderived peptides on autoAb production and disease.

\section{Methods}

\section{Mice}

Female BWF1, (BALB/c $\times$ NZW) F1 [CWF1], BALB/c and NZW mice were bred in the UCLA Rheumatology Vivarium. In vivo experiments were done under an approved protocol in accordance with UCLA Animal Research Committee guidelines.

CWF1 $\left(\mathrm{H}-2^{\mathrm{d}, \mathrm{u}}\right), \mathrm{BALB} / \mathrm{c}\left(\mathrm{H}-2^{\mathrm{d}}\right)$, and NZW $\left(\mathrm{H}-2^{\mathrm{u}}\right)$ are nonautoimmune strains bearing MHC class II molecules identical or similar to those in BWF1 $\left(H-2^{d, u}\right)$. (Since NZW class II genes I-A ${ }^{u}$ and I-E ${ }^{z}$ are identical to I- $\mathrm{A}^{\mathrm{u}}$ and I- $\mathrm{E}^{\mathrm{u}}$, respectively, we have used the latter throughout this report [14]). To confirm that CWF1 mice do not spontaneously develop autoimmune disease, 20 male and 20 female CWF1 mice were monitored until $52 \mathrm{wk}$ of age. Survival was $100 \%$ at $52 \mathrm{wk}$; none had proteinuria or increased blood urea nitrogen; a small number of older female animals developed a low serum level of autoAbs.

1. Abbreviations used in this paper: Ag, antigen; ds, double stranded; HEL, hen egg lysozyme; MNC, mononuclear cells; SI, stimulation in$\operatorname{dex}$; $T$, $T$ helper cells; $V_{H}$, variable region of heavy chains. 
Table I. T Cell Determinant and Control Peptides Used in Tolerance Experiments

\begin{tabular}{llc}
\hline \multicolumn{1}{c}{ Peptide } & \multicolumn{1}{c}{ Sequence } & $\begin{array}{c}\text { Spontaneous } \\
\text { proliferation of } \\
\text { unprimed BWF1 } \\
\text { T cells }\end{array}$ \\
\hline 1 A6H 34-45 (p34) & MNWVKQSHGKSL & + \\
2 A6H 58-69 (p58) & FYNQKFKGKATL & + \\
3 A6H 84-95 (p84) & SEDSALYYCARD & + \\
4 A6H 11-22 (p11) & LVKPGASVKMSC & - \\
5 A6H 93-107 (p93) & ARDSPYYYGSSYGFA & - \\
6 HEL 106-116 (p106) & NAWVAWRNRCK & - \\
\hline
\end{tabular}

Peptides 1-5 were derived from the $\mathrm{V}_{\mathrm{H}} \mathrm{D}$ of $\mathrm{mAb}$ A6.1. The first three are $\mathrm{T}$ cell determinants able to spontaneously prime for a proliferative response; peptides 4 and 5 do not elicit spontaneous $T$ cell proliferation from naive BWF1 mice but induce modest to strong $T$ cell proliferation upon immunization (data not shown). Peptide 6 is an immunodominant peptide of HEL; it elicits vigorous T cell proliferative and $A b$ responses upon immunization of BWF1 mice, but it is not recognized by unprimed BWF1 T cells. Peptides p34 and p106 bind MHC class II molecule I-E $E^{\mathrm{d}}, \mathrm{p} 84$ and $\mathrm{p} 93$ bind I-A $\mathrm{A}^{\mathrm{u}}$, and p58 binds both I-E $\mathrm{E}^{\mathrm{d}}$ and $\mathrm{I}^{\mathrm{u}} \mathrm{E}^{\mathrm{C}}$ (28). The full sequence of mAb A6.1 has been published (5).

\section{Peptides}

12- or 15-mer overlapping peptides representing the entire $V_{H} D$ region sequence of three anti-DNA mAbs (A6.1, BWds3, and 5GD5) and one $\mathrm{mAb}$ (HYHEL-5) to an exogenous Ag, hen egg lysozyme (HEL) were synthesized. All four $\mathrm{mAbs}$ use the $\mathrm{V}_{\mathrm{H}} \mathrm{J} 558$ gene family. Characteristics of anti-DNA mAbs are as follows $(4,5)$ : all are IgG2a derived from BWF1 mice; all bind single-stranded and double-stranded (ds) DNA with high avidity $\left(K_{d} 10^{-9} \mathrm{M}\right)$; all fix complement well; and D gene families used by these mAbs differ (FL16.1 and Dsp2,3). HYHEL-5, an IgG2a mAb, uses a D segment from the Dsp2 family (15).

For initial screening experiments shown in Figs. 1 and 2, the pin synthesis method $(16,17)$ was used. For experiments in Fig. 1, a total of 411 12-mer peptides were synthesized to recapitulate the sequence of 100-110 amino acids in the $\mathrm{V}_{\mathrm{H}} \mathrm{D}$ of four different $\mathrm{mAbs}$. For experiments in Fig. 2, 94 15-mer peptides representing $\mathrm{V}_{\mathrm{H}} \mathrm{D}$ of $\mathrm{BWds} 3 \mathrm{mAb}$ were made. Each peptide overlapped its neighbor by all but one residue.

Large quantities of selected 11-15-mer peptides were synthesized at the UCLA Peptide Synthesis Facility, using Fmoc chemistry (Table I). The synthetic peptides were analyzed for purity by HPLC and by mass spectrometry. Each peptide chromatographed essentially as a sharp single peak. All purified peptides were found to have the expected molecular mass.

\section{Spontaneous $T$ cell proliferation elicited by $\mathrm{Ig}$ peptides}

For experiments shown in Figs. 1 and 2, whole splenic mononuclear cells (MNC) were pooled from 10-12 mice aged 12-14 wk and purified as MNC on Ficoll-Hypaque gradients. Splenic MNC (5-10 $\times 10^{5}$ per well) were incubated in triplicate with $10 \mu \mathrm{M}$ (the optimal concentration) peptide in $200 \mu \mathrm{HL}-1$ medium (Ventrex Laboratories, Portland, ME) containing $2 \mathrm{mM}$ glutamine. After $48 \mathrm{~h}$ of incubation at $37^{\circ} \mathrm{C}$ in $7 \% \mathrm{CO}_{2}, 1 \mu \mathrm{Ci}$ of $\left[{ }^{3} \mathrm{H}\right]$ thymidine was added to each well; $16-18 \mathrm{~h}$ later, the cells were harvested by a Titertek cell-harvester (Skatron, Norway), and beta emissions were counted. Results are expressed as stimulation index (SI). The SI is the ratio of mean cpm obtained in response to $\mathrm{Ag}$ versus mean cpm of cells with medium only.

In separate experiments, T cell-enriched splenic MNC $\left(1-5 \times 10^{5}\right.$ per well) were cultured with syngeneic irradiated spleen cells as antigenpresenting cells $\left(3-6 \times 10^{5}\right.$ ) and 1-10 $\mu \mathrm{M}$ of peptides. Enrichment of splenic cells for $\mathrm{T}$ cells was done by passing the MNC over nylonwool columns containing goat anti-mouse IgG (BioTex Laboratories,
Edmonton, Canada). After two passages, the cells in the effluent were $>90 \% \mathrm{~T}$ cells, as measured by killing after incubation with anti-T "cocktail" (anti-Thy1.2 + anti-L3T4 + complement; Accurate Chemical and Science Corp., Westbury, NY).

\section{Intravenous (i.v.) high-dose tolerance}

Effect on peptide-specific $T$ cell responses. 8-wk-old BWF1 mice were injected i.v. with $300 \mu \mathrm{g}$ of peptide in $100 \mu \mathrm{l}$ PBS or with $100 \mu \mathrm{l}$ of saline alone. After $10 \mathrm{~d}$, both groups of mice were immunized subcutaneously with $25-50 \mu \mathrm{g}$ of peptide in CFA. $9 \mathrm{~d}$ later, draining lymph node cells $\left(5 \times 10^{5}\right.$ per well $)$ were incubated in HL-1 medium with 2 $\mathrm{mM}$ glutamine with different concentrations of peptide or with purified protein derivative ( $700 \mathrm{U} / \mathrm{ml}$; Evans Medical Ltd., Liverpool, UK) for $4 \mathrm{~d}$. The culture wells were pulsed with $1 \mu \mathrm{Ci}\left[{ }^{3} \mathrm{H}\right]$ thymidine $18 \mathrm{~h}$ before the end of culture. Cells in each well were collected onto filtermat A papei (Wallac, Gaithersburg, MD) with a semiautomatic cell harvester (Skatron Inc., Sterling, VA), and beta emissions were measured.

To determine the effect of i.v. peptide treatment on peptide-specific Abs, peptide- and saline-pretreated mice were bled 10-12 d after challenge immunizations. The sera were tested for IgG antipeptide $\mathrm{Ab}$ by ELISA. 96-well plates (Costar Corp., Cambridge, MA) were coated with $0.3-0.6 \mu \mathrm{g} /$ well of peptide or peptide-keyhole limpet hemocyanin conjugates (17) overnight at $4^{\circ} \mathrm{C}$. After blocking with $10 \%$ FCS in PBS, test sera were added at serial dilutions. Bound $\mathrm{Ab}$ was detected with alkaline phosphatase-conjugated goat anti-mouse IgG (Fisher Scientific, Pittsburgh, PA). Reactions were developed with $p$-nitrophenylphosphate (Sigma Chemical Co., St. Louis MO), and absorbance at 405 nm was read using an ELISA reader (M600; Dynatech Laboratories Inc., Chantilly, VA).

\section{i.v. high dose tolerance}

Effect on clinical disease. Prenephritic 12- to 15-wk-old BWF1 mice were treated i.v. with single or multiple injections of $300 \mu \mathrm{g}$ to $1 \mathrm{mg}$ of Ig peptides, singly or in combination. Details are given in figure legends. Control mice received injections of similar volumes of saline, a foreign peptide (HEL p106) or a combination of two nonstimulatory peptides from $A 6.1 V_{H} D$. Animals were monitored for survival and clinical disease.

Proteinuria was estimated by examination of fresh morning urine using albustix (Ames Co., Elkhart, IN) on a scale of 0 to $4+$, where $0 /$ trace $=$ negative, $1+=30,2+=100,3+=300$, and $4+=$ over $2,000 \mathrm{mg} / \mathrm{dl}$. Severe proteinuria was defined as $\geq 3+$ on at least two consecutive examinations. Plasma creatinine was estimated by a colorimetric method using kits and standards purchased from Stanbio Laboratory, Inc. (San Antonio, TX). In adult BALB/c and young prenephritic BWF1 mice, plasma creatinine levels ranged from 0.3 to $0.6 \mathrm{mg} / \mathrm{dl}$. Anti-dsDNA Ab were measured in serum samples by a standard ELISA assay using calf thymus DNA, as previously described (5). Mean triplicate OD 405-nm values were recorded at serial serum dilutions. AntidsDNA titers are expressed as $\mathrm{U} / \mathrm{ml}$, using a positive reference standard of pooled serum from 8-mo-old BWF1 mice. A 1:100 dilution of this standard serum was arbitrarily assigned a value of $100 \mathrm{U} / \mathrm{ml}$.

\section{Statistical analysis}

Analysis of survival and nephritis (proportion of mice without severe proteinuria) was done by log rank and chi-square tests. Mean antidsDNA Ab and plasma creatinine levels and mean age at severe proteinuria and survival were compared using Student's $t$ test.

\section{Results}

BWF1 mice develop spontaneous $T$ cell proliferation to several $V_{H}$ region determinants from autoAbs but not to peptides from a nonautoreactive $\mathrm{mAb}$

We measured the proliferative response of $T$ cells from unimmunized young BWF1 mice to 12-mer overlapping peptides derived from the $\mathrm{V}_{\mathrm{H}} \mathrm{D}$ regions of three anti-DNA mAbs and 

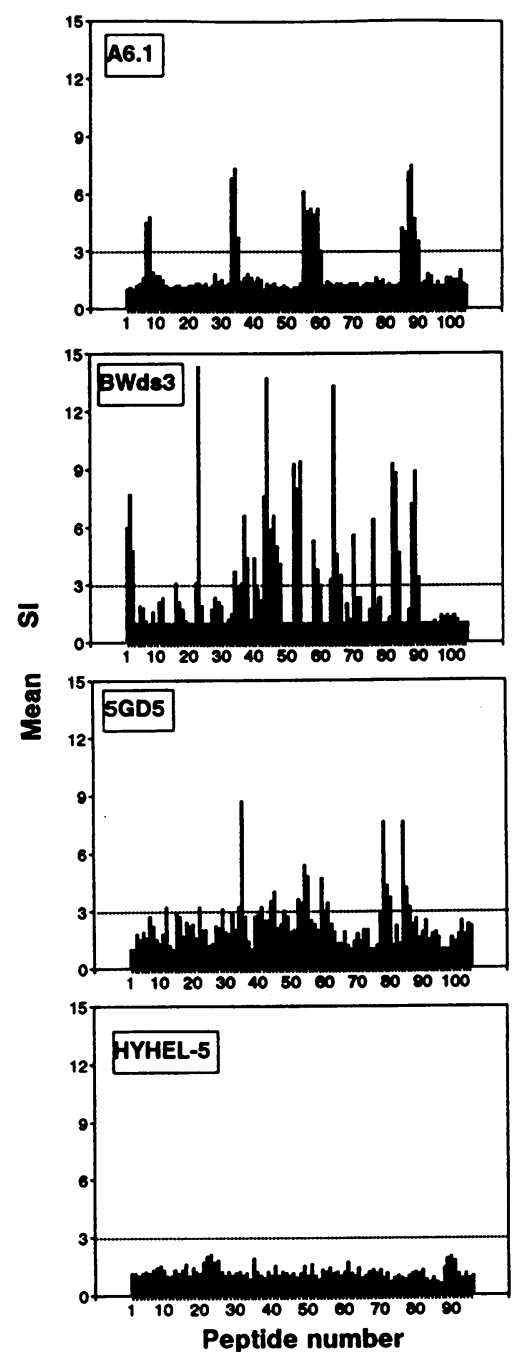

Peptide number
Figure 1. Presence of spontaneous $\mathrm{T}$ cell proliferative responses to $\mathrm{V}_{\mathrm{H}} \mathrm{D}$ region determinants in three different IgG anti-DNA mAbs but their absence in one $\mathrm{mAb}$ antiHEL. Results are shown as the means of the mean triplicate SI from three different experiments for each $\mathrm{mAb}$, using separate spleen cell pools from 12-14-wk-old BWF1 mice. Background (cells with medium only) cpm values ranged from 557 to 3,132; positive control concavalin A cpm values ranged from 23,421 to 122,058 (in a total of 12 experiments). The SEM for the mean SI was $<15 \%$. Dotted horizontal lines indicate an SI of 3.0. Each panel in the figure is labeled with the designation of the mAb from which 12-mer peptides were synthesized. Each $\mathrm{x}$-axis shows the number of the peptide, i.e., peptide 1 represents amino acids 1-12 from the A6.1 $\mathrm{H}$ chain in the first panel, 1-12 from BWds3 in the second panel, etc.; peptide 2 represents amino acids $2-13$, etc.

one control nonautoreactive $\mathrm{mAb}$. These peptides were cultured with splenic MNCs pooled from 10-12 mice, aged 12-14 wk. The mean SI from three experiments performed for each $\mathrm{mAb}$ are shown in Fig. 1. A positive response was defined as a SI of 3.0 or greater. A T cell determinant was defined by the presence of positive spontaneous responses to at least two contiguous peptides. Similar determinants in certain locations in all three anti-DNA mAbs were consistently detected. No determinants were detected in the anti-HEL mAb, HYHEL-5, in any of three experiments. Similar results were obtained when $T$ cell-enriched splenic MNCs were cultured with syngeneic irradiated spleen cells as Ag-presenting cells and 1-10 $\mu \mathrm{M}$ of peptides (data not shown). This suggests that $T$ cells from young BWF1 mice have been spontaneously primed to $V_{H}$ region determinants of autoAbs but not to peptides from a nonautoreactive $\mathrm{Ab}$.

To confirm the validity of assays with pin-synthesized peptides, several spontaneous $T$ cell determinants and many nonstimulatory peptides identified in Fig. 1 were synthesized on a large scale using Fmoc chemistry. These peptides at various concentrations were incubated with purified splenic $T$ cells from individual 12-14-wk-old unimmunized BWF1 (or with pools

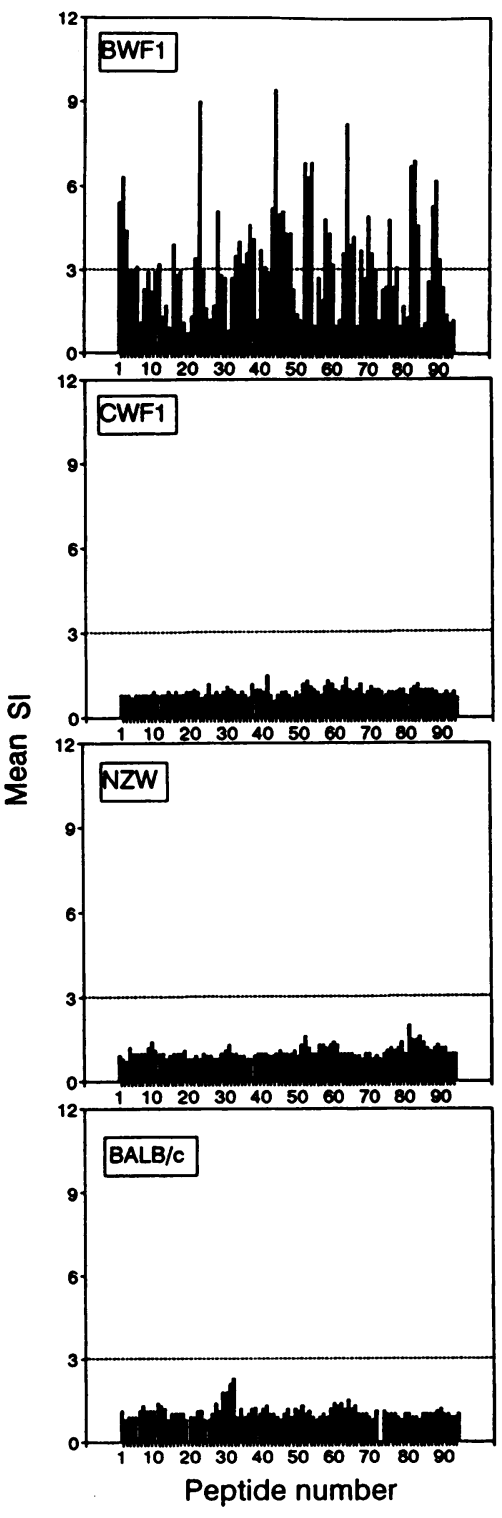

Figure 2. Abundance of $T$ cell determinants in autoimmune BWF1 mice, but their absence in nonautoimmune strains bearing similar or identical MHC class II molecules. $\mathrm{T}$ cell proliferative responses are expressed as the overall mean of the mean triplicate SI in three different experiments in each mouse strain. 15-mer overlapping synthetic peptides ( $n=94$ ) representing the $V_{H} D$ region of $m A b$ BWds3 were incubated with spleen cell pools from autoimmune (BWF1) and class IImatched nonautoimmune mice of different strains (CWF1, BALB/ c, and NZW). Background cpm values ranged from 567 to 3,209; concavalin Apositive control values ranged from 40,186 to 260,546 (in a total of 12 experiments). The SEM for each triplicate was $<15 \%$. Dotted horizontal lines indicate an SI of 3.0 .

of splenic T cells from several mice) and syngeneic Ag-presenting cells. Results were similar to those obtained with pinsynthesized peptides. Stimulation indices of 4-10 were detected only with determinants that were stimulatory in studies shown in Fig. 1, whereas SI were $<1.5$ with nonstimulatory Ig peptides or with a foreign peptide (HEL p106).

Spontaneous $T$ cell determinants are detected in the autoimmune BWF1, but not in nonautoimmune strains

To determine whether spontaneous $\mathrm{T}$ cell proliferation to these autoAb-derived determinants is restricted to autoimmune BWF1 mice, 15-mer peptides, each overlapping its neighbor by 14 amino acids representing the $\mathrm{V}_{\mathrm{H}} \mathrm{D}$ of $\mathrm{BWds} 3$ anti-DNA mAb, were incubated with splenic MNC pooled from 12-14-wk-old mice of various strains bearing identical or similar MHC class II, including BWF1 (H-2,u $)$ CWF1 (H-2 d,u $)$ BALB/c (H$2^{d}$ ), and NZW (H-2 $\left.{ }^{u}\right)$ mice. We found that many determinants elicited proliferation of autoimmune BWF1 T cells but not $\mathrm{T}$ cells from the MHC-matched nonautoimmune strains (Fig. 2). This suggests that spontaneous recognition of Ig-derived peptides is a property of the autoimmune strain. 
$T$ cell determinants appear before the onset of clinical disease

To determine the chronology of development of spontaneous $\mathrm{T}$ cell activation to these determinants, we repeated the above mentioned experiments in BWF1 mice of different age groups: $6-10,12-14,16-20$, or $>20 \mathrm{wk}$. In spleen pools or in spleens from individual mice, significant $\mathrm{T}$ cell proliferative responses (SI 3.0) were not seen in naive mice aged 6-10 wk. Maximal proliferative responses were detected in mice aged 12-14 wk. By the time the BWF1 mice had reached the age of $20 \mathrm{wk}$, proliferative responses had become weaker, even to mitogens (data not shown), as reported by others $(18,19)$. In other BWF1 females from our facility studied at the same time, circulating IgG anti-DNA Ab were first detected in serum at 12-16 wk of age; glomerular deposits of IgG and proteinuria began at 18-22 wk (data not shown). This is consistent with earlier observations in our colonies $(3,20)$. Thus, spontaneous $\mathrm{T}$ cell autoimmunity to these determinants develops simultaneously with the appearance of circulating IgG autoAbs and before development of clinical and pathological signs of lupus.

\section{In vivo tolerance to $V_{H}$ determinants}

Effect on peptide-specific $T$ cell proliferation and $\operatorname{IgG}$ Abs in $B W F 1$ mice. It is known that high doses of $\mathrm{Ag}$ can suppress immune responses in normal adult animals (21). To determine if high doses of self peptides would result in similar Ag-specific unresponsiveness in lupus-prone mice, we administered $300 \mu \mathrm{g}$ i.v. of peptides in adult BWF1 mice and measured peptidespecific responses upon subsequent peptide immunization. We found that i.v. injections of any of three $V_{H} D$ determinants resulted in profound peptide-specific unresponsiveness as measured by $\mathrm{T}$ cell proliferation and serum IgG antipeptide $\mathrm{Ab}$ (Fig. 3).

\section{$T$ cell tolerance to autoAb-derived peptides}

Effect on clinical disease. To assess the in vivo importance of autoAb-derived peptides in disease, we induced i.v. high dose tolerance to selected $\mathrm{T}$ cell determinants and measured effects on anti-DNA and glomerulonephritis. Young (12-wk-old) BWF1 mice were treated with $300 \mu \mathrm{g}$ of each of three determinants ( $\mathrm{p} 34, \mathrm{p} 58$, and $\mathrm{p} 84$ ) from $\mathrm{A6.1} \mathrm{V}_{\mathrm{H}}$, either singly or in combination (Table II). Control BWF1 mice received a foreign peptide (HEL p106) or saline. Mice treated with any of the three determinants singly had a small but significant delay in the development of IgG anti-DNA Ab compared to saline or HEL p106 treated mice (A). This delay in autoAb production by individual determinants was not associated with significant delay in nephritis or improved survival (B). However, mice treated with a combination of all three peptides had a significant delay in disease, as characterized by significantly delayed onset of severe proteinuria, decreased mean plasma creatinine levels, and increased mean survival, which was associated with a more pronounced and prolonged decrease in anti-DNA Ab levels ( Table II).

To further confirm the effect of tolerization to a combination of three determinants on clinical disease, 14-wk-old BWF1 mice were injected with $1 \mathrm{mg}$ i.v. of each of three determinants or of each of two control peptides derived from A6.1 $\mathrm{V}_{\mathrm{H}} \mathrm{D}$ ( $\mathrm{p} 11$ and p93). BWF1 mice tolerized with a combination of all three determinants had significant decreases in the mean serum IgG anti-dsDNA $\mathrm{Ab}(P<0.01$ to $<0.05)$, the mean plasma creatinine levels $(P<0.01$ to $<0.05)$, and the proportion of mice

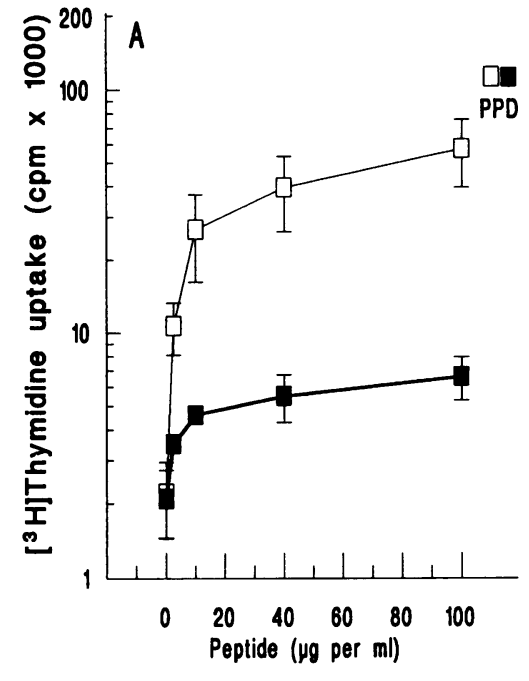

Figure 3. i.v. administration of self-autoAb-derived peptides induces peptide-specific unresponsiveness as measured by $\mathrm{T}$ cell proliferation and peptide-specific IgG $\mathrm{Ab}$ in BWF1 mice. 8-wk-old BWF1 mice received saline alone or $300 \mu \mathrm{g}$ of p84 in PBS i.v. (day 1), then were immunized $10 \mathrm{~d}$ later with p84 in CFA (day 10). Draining lymph node cell proliferation was done on day 19 (i.e., at the age of 11 wk). (A) T cell proliferation to p84 is expressed as the mean $( \pm$ SEM) of the mean

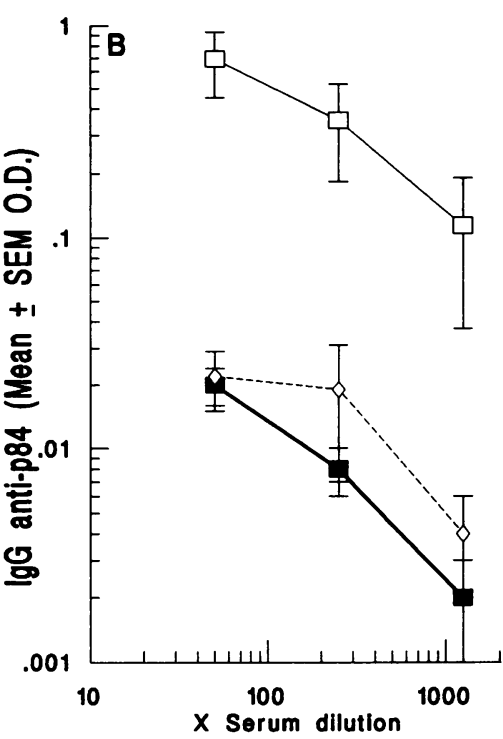
cpm in triplicate wells from four mice in each group. Negative (medium alone) and positive purified protein derivative $(P P D)$ control cpm values were equivalent in peptide (a) - and saline $(\square)$-pretreated mice. $(B)$ Peptide-specific (antip84) IgG Ab detection is expressed as units of OD at $405 \mathrm{~nm}$. The mean ( \pm SEM) of mean triplicate OD values are shown from six mice in each group. The background mean OD values from six age-matched unmanipulated $(\diamond)$ BWF1 mice are also shown. Note that p84-pretreated mice had a profound decrease in peptide-specific T cell proliferation $(P<0.05$, Student's $t$ test) and IgG Ab production $(P<0.05)$ compared to saline-pretreated mice. Data are from one of two similar experiments. Similar results were obtained with other $\mathrm{T}$ cell determinants (p34 and p58) (data not shown).

developing severe proteinuria $(P<0.01$ to 0.05$)$ compared to saline or control peptide treated mice (Fig. $4 A-C$ ). This improvement in nephritis and anti-DNA Ab correlated with a significant increase in life expectancy. At $42 \mathrm{wk}$ of age, survival in the combined peptide group was $100 \%$ compared to $37.5 \%$ in both control groups $(P<0.05) .50 \%$ animal survival was increased by 7-9 wk in the combination group compared to saline and control peptide treatments, respectively. Overall survival by log rank test was also significantly prolonged in mice in the combination group compared to mice in control treatment groups (Fig. $4 \mathrm{D}$ ).

\section{Discussion}

We have examined the possibility that $\mathrm{B}$ cells making autoAb may be upregulating their production through the processing of their own Ig molecules, thereby activating a reciprocal $\mathrm{T}$ cell 
Table II. Effect of i.v. Treatment with Peptides on Anti-DNA Ab and Clinical Disease

\begin{tabular}{|c|c|c|c|c|c|c|}
\hline & Saline & p34 & p58 & p84 & Combination & HEL p106 \\
\hline \multicolumn{7}{|l|}{ A. IgG anti-DNA Ab (U/ml) } \\
\hline \multicolumn{7}{|l|}{ Age (wk) } \\
\hline 18 & $26 \pm 8.8$ & $3.6 \pm 1.2 *$ & $5.8 \pm 1.6 *$ & $13 \pm 9.5$ & $3.3 \pm 1.6^{*}$ & $32 \pm 11$ \\
\hline 21 & $31 \pm 9.2$ & $9.7 \pm 5.5^{\ddagger}$ & $17 \pm 9.1$ & $13 \pm 3.2^{\ddagger}$ & $1.1 \pm 0.6 *$ & $42 \pm 12$ \\
\hline 24 & $69 \pm 11$ & $55 \pm 12$ & $46 \pm 6.3^{\ddagger}$ & $56 \pm 1.8^{\ddagger}$ & $23 \pm 7.3 *$ & $80 \pm 6.1$ \\
\hline 27 & $100 \pm 11$ & $76 \pm 7.2$ & $85 \pm 5.8$ & $96 \pm 18$ & $42 \pm 13^{*}$ & $108 \pm 16$ \\
\hline \multicolumn{7}{|l|}{ B. Nephritis and survival } \\
\hline Plasma creatinine (mg/dl at $27 \mathrm{wk})$ & $1.38 \pm 0.2$ & $0.96 \pm 0.2$ & $1.24 \pm 0.4$ & $1.1 \pm 0.2$ & $0.51 \pm 0.1^{8}$ & $1.44 \pm 0.4$ \\
\hline Mean age $(w k)$ at $\geq 3+$ proteinuria & $33.8 \pm 1.6$ & $35.4 \pm 2.4$ & $34.9 \pm 1.5$ & $33.1 \pm 1.7$ & $40.9 \pm 1.9^{8}$ & $31.3 \pm 1.6$ \\
\hline Mean survival (wk) & $40.7 \pm 2.1$ & $40.9 \pm 2.4$ & $40.9 \pm 1.8$ & $40.4 \pm 2.1$ & $47.0 \pm 2.1^{\S}$ & $39.0 \pm 2.2$ \\
\hline
\end{tabular}

Groups of eight 12-wk-old BWF1 mice were treated with three determinants singly or in combination (p34 + p58 + p84), a control peptide HEL p106, or saline. Animals received $300 \mu \mathrm{g}$ of individual peptide or saline i.v. once every $2 \mathrm{wk}$ from 12 to $20 \mathrm{wks}$ of age. Results are expressed as the mean \pm SEM. Mean \pm SEM values in mice treated with $V_{H}$ determinants were compared with the findings in saline- or HEL p106-treated mice by Student's $t$ test. Statistically significant findings in $\mathrm{V}_{\mathrm{H}}$ determinant treated mice compared to both control groups are shown in bold. There was no significant difference in any finding between the two control groups (saline vs HEL p106). The mice treated with any of three determinants singly had a small but significant decrease in the anti-DNA Ab compared to saline- or HEL p106-treated mice, but the effect was lost by 27 wk. More significant and prolonged decrease in the anti-DNA Ab was seen in mice treated with a combination of peptides. The group of mice tolerized with a combination of peptides also had a significant improvement in clinical disease: the mean plasma creatinine at 27 wk and mean age at the development of severe proteinuria were decreased and mean survival was increased. ${ }^{*} P<0.01$ to $<0.05$ (Student's $t$ test) compared to both control groups (saline and HEL p106); ${ }^{\ddagger} P<0.01$ to $<0.05$ compared to HEL p106 group; ${ }^{8} P<0.01$ to $<0.05$ (Student's $t$ test) compared to saline and HEL p106 treatments.

help. Tolerance induction of the self-Ig-reactive $\mathrm{T}$ cells interferes with this circuit and decreases autoimmune manifestations in murine lupus, demonstrating its importance in the disease.

Spontaneous $T$ cell priming to $V_{H}$ region determinants occurs in BWF1 mice, but why? Our findings suggest that $\mathrm{T}$ cells in young BWF1, but not in MHC-matched nonautoimmune mice, have been spontaneously primed to $V_{H}$ region determinants of autoAbs. Possible reasons for this include $(a)$ selection of a $\mathrm{T}$ cell repertoire that recognizes these peptides particularly well (a repertoire which should normally be forbidden by tolerance mechanisms), ( $b$ ) failure to develop suppressive cellular and/or idiotypic circuits, (c) hybrid class II molecules (14) that present such peptides more efficiently, and $(d)$ unusually effective cross-stimulation of $B$ and $T$ idiopeptide-specific cells leading to broad determinant spreading $(22,23)$. Experiments are in progress to explore the mechanisms by which the initial Ig peptide recognition is promoted, and the failure of these mice to activate appropriate downregulating responses.

How are the Ig determinants generated in spontaneous disease? B cells process surface as well as endogenous forms of Ig that are neither expressed on the cell surface nor secreted, and some of the resulting peptides are presented by class II to $T$ cells (10-13). Processing and presentation of endogenous Ig by class II must be an efficient process since naturally processed Ig peptides are readily eluted from class II molecules (24-26). Accordingly, self-Ig V region peptides may participate in shaping the $\mathrm{T}$ cell repertoire as well as playing an important role in immune regulation $(10-13,27)$.

It was intriguing, however, that we did not detect spontaneous in vitro $\mathrm{T}$ cell proliferative response to the intact auto $\mathrm{Ab}$ molecule. Secreted forms of self-Ig may not be internalized/ processed efficiently enough to generate sufficient quantities of the relevant peptides for class II binding. Furthermore, some determinants in the intact $\mathrm{Ab}$ molecule may activate Th1 cells, others Th2 cells, or still others regulatory/suppressive cells, and the sum total functional response to the whole molecule may not be detectable. Even after immunization with $\mathrm{mAb}$ in CFA, proliferation of BWF1 T cells to the whole molecule is detectable, but it is weaker than the response to the immunodominant peptide (28).

AutoAb-derived determinants may play a role in disease pathogenesis in BWF1 mice. The spontaneous $\mathrm{T}$ cell responses emerge simultaneously with the appearance of low levels of circulating IgG anti-DNA. As Ab responses to DNA mature, some somatic mutations will occur that introduce new $\mathrm{T}$ cell determinants into IgG autoAbs $(10,29)$. The increasing levels of anti-DNA should provide a continuous source of these peptides.

Since self-autoAb peptide-reactive $T$ cells appear before the onset of clinical disease, they may be critically involved in amplification of autoAb production and disease pathogenesis. In previous work, immunization of young BWF1 mice with any of the three MHC-binding peptides from A6.1 $\mathrm{V}_{\mathrm{H}} \mathrm{D}$ (p34, p58, and p84) accelerated IgG anti-DNA production and clinical disease $(17,28)$. Furthermore, these peptides incubated with $T$ and B cells from young BWF1 mice increase IgG anti-DNA production in vitro $(30)$.

Tolerization to a combination of three $V_{H}$ region determinants from an anti-DNA mAb delays onset of disease. Peptidespecific $T$ cell tolerance to a combination of all three peptides was associated with a significant delay in the development of anti-DNA Ab and nephritis, as well as prolonged survival. The effect on disease may be due to the induction of tolerance through deletion or anergy of autoreactive Th cells; similarly in experimental allergic encephalomyelitis, i.v. injection of myelin basic protein resulted in deletion of autoreactive $\mathrm{T}$ cells and abrogation of clinical disease (21). The increase in survival in our mice treated with three peptides was $\sim 10 \mathrm{wk}$, amounting to $\sim 25 \%$ extension of life span. To investigate this further, we determined the kinetics of i.v. high dose tolerance: of eight 

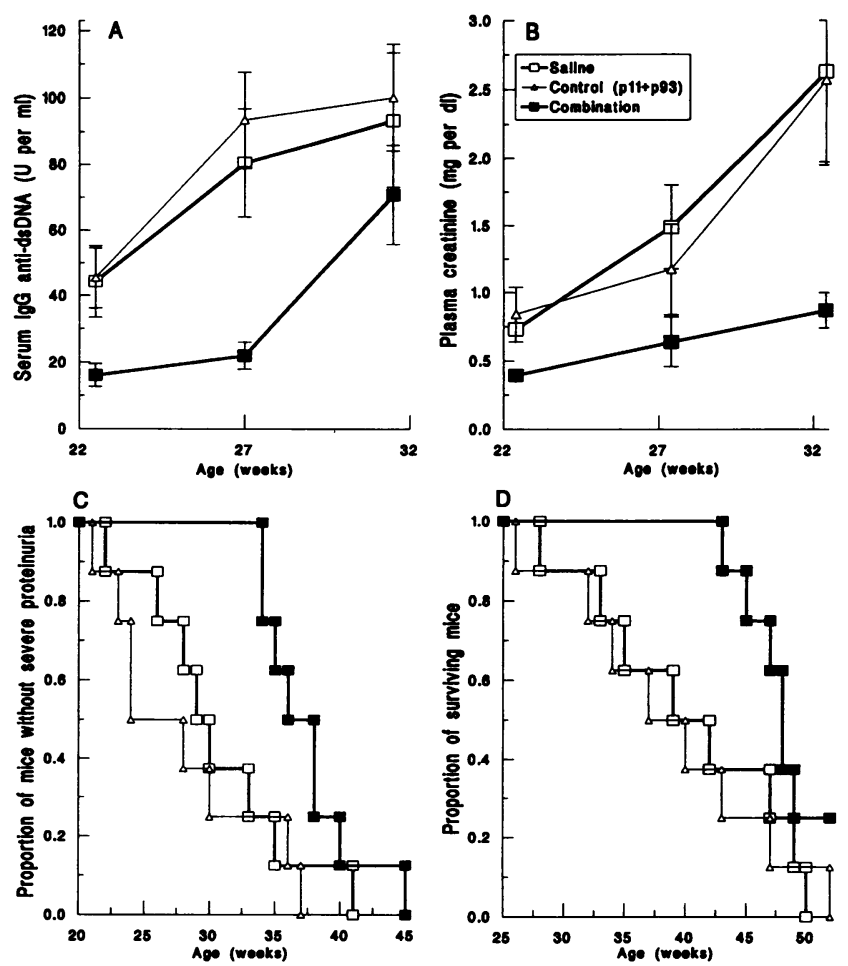

Figure 4. i.v. treatment of young BWF1 mice with a combination of three determinants ( $\mathrm{p} 34, \mathrm{p} 58$, and $\mathrm{p} 84$ ) resulted in prolonged survival and delayed development of nephritis and IgG anti-DNA Ab. Groups of eight 14-wk-old BWF1 mice received $1 \mathrm{mg}$ i.v. of each of three determinants (Combination, $\square$ ), $1 \mathrm{mg}$ each of two control nonstimulatory $\mathrm{V}_{\mathrm{H}} \mathrm{D}$ peptides $(p 11+p 93, \Delta)$, or saline $(\square)$. The mean $( \pm \mathrm{SEM})$ values of serum IgG anti-dsDNA $\mathrm{Ab}(A)$ and plasma creatinine $(B)$ were significantly decreased in the combination-treated group compared to their levels in both control groups $(P<0.01$ to $<0.05$ at 22 and $27 \mathrm{wk}$, Student's $t$ test). By 32 wk the differences were not significant. (C) Proportion of mice without severe proteinuria ( $\geq 3+$ on at least two consecutive examinations) versus age in wk is shown. A decreased proportion of combination-treated mice had severe proteinuria compared to those treated with control $\mathrm{V}_{\mathrm{H}} \mathrm{D}$ peptides $(P<0.01)$ or with saline $(P<0.05)$ (log rank test). (D) Survival was significantly prolonged in mice treated with a combination of determinants compared to controls. At 42 wk, survival was $100 \%$ in the combination group compared with $37.5 \%$ in both control groups $(P<0.05$, chi-square test with Yates correction). Survival analysis by log rank test showed prolonged life in mice treated with a combination compared to mice treated with saline $(P=0.05)$ or with control $\mathrm{V}_{\mathrm{H}} \mathrm{D}$ peptides $(P=0.011)$.

tolerized mice, none had IgG anti-peptide Ab 2 or 4 wk after tolerance was induced; however, by 8-12 wk, three of eight mice had developed low levels of antipeptide Ab (data not shown), suggesting an escape from tolerance. Alternatively, after an interval of tolerance, these mice developed $\mathrm{T}$ cells recognizing different determinants that activated help for antiDNA Ab. Thus, escape from tolerance as well as determinant spreading as the disease progresses, may be responsible for the limited duration of benefit.

Possible mechanisms by which manipulation with determinants from a single $V_{H}$ region affect the disease process. The predictable immunogenic and tolerogenic effects of Ig-derived determinants in BWF1 mice support the notion that the initial $\mathrm{T}$ cell response against components of the $\mathrm{Ag}$ receptor ( $\mathrm{Ig}$ on $B$ cells) may play a role in amplification of the basal $T$ cell help for autoAb in genetically susceptible individuals with appropriate $\mathrm{T}$ cell repertoires. This $\mathrm{Th}-\mathrm{B}$ circuitry may be involved in the pathogenesis of lupus, using some of the following mechanisms: (a) An Ig peptide that mimics a determinant on a self$\mathrm{Ag}$ can induce or perpetuate autoimmunization. It has been shown that strikingly different antigenic peptides can crossreact with individual $\mathrm{T}$ cell clones (31). Immunization with an Ig light chain, which has a sequence homology with a 70 kD U1 RNP polypeptide, elicits autoAb against the U1 RNP autoantigen and DNA in BALB/c mice (32). (b) Ig determinants may serve the role of maintaining autoimmunity, which has been induced in the first place by an as yet unknown "initiating" Ag. A perpetual supply of peptides from autoAb may keep autoreactive Th cells activated and autoAb production maintained. (c) Because spontaneous autoimmunity to these peptides precedes clinical disease, they may have a role in disease induction as primary autoantigen(s). Natural autoAb and CD5 cells could provide one early source of these peptides. Peptides from natural autoAb may activate Th cells capable of providing help for anti-DNA Ab in individuals with an appropriate $T$ cell repertoire.

It may appear that tolerization to three determinants from a single $\mathrm{V}_{\mathrm{H}}$ region had an overall effect on disease, since the antiDNA and other autoAbs use diverse $V_{H}$ regions. However, there is strong evidence for limited $\mathrm{B}$ cell clonality, dominance of the BWF1 auto $A b$ repertoire by $V_{H} J 558$-encoded $I g$, and recurring use of similar sequences in multiple anti-DNA mAbs (5, $33,34)$. Sequences very similar to these determinants are commonly found in murine anti-DNA Abs (see sequences in references 5, 34-39), which would explain the general effect of these peptides on disease.

It is likely that certain critical $\mathrm{V}_{\mathrm{H}} \mathrm{J} 558$ idiopeptide-recognizing Th cells serve as key inducers of B cell hyperreactivity. Owing to reciprocal and sequential T-B interactions, at each stage the likelihood of further enlistment of Ig peptide crossreactive lymphocytes will occur. Therefore, tolerance induction to prototype peptides which are similar throughout this gene family might have a potent effect in stemming a tide of Thstimulated B cell recruitment.

In summary, lupus mice spontaneously activate $T$ cells capable of reacting to auto $\mathrm{Ab}$-derived $\mathrm{V}$ region peptides that have escaped the tolerance process. Several observations and arguments presented above suggest that activation by direct $T-B$ interactions with autoAbs engendering the peptide stimulus is an important and specific abnormality in a murine lupus model. In these experiments, extrinsic downregulation of this $\mathrm{Ag}$ receptor-based pathway significantly delayed disease. It is interesting that only three of the many critical determinants likely to be involved in the process were sufficient to delay the disease; this suggests that the identity of the initial autoantigen(s) is less important than the degree of connectance/cross-reactivity in Th-B interactions.

\section{Acknowledgments}

We thank J. Jacinto for technical assistance, and Drs. K. Moudgil and B. Tsao for critically reading the manuscript.

This work was supported by the U.S. Department of Health and Human Services grants (RO1-AR33962, P-60-AR-36834, and PO1AR40919), an Arthritis Foundation fellowship (R. R. Singh), and J. Dreyfuss and B. Maltz Laboratories. 


\section{References}

1. Hahn, B. H. 1993. An overview of the pathogenesis of systemic lupus erythematosus. In Dubois' Lupus Erythematosus, 4th ed. D. J. Wallace and B. H. Hahn, editors. Lea and Febiger, Philadelphia. 65-70.

2. Theofilopoulos, A. N., and F. J. Dixon. 1985. Murine models of systemic lupus erythematosus. Adv. Immunol. 37:269-390.

3. Hahn, B. H. 1993. Animal models of systemic lupus erythematosus. In Dubois' Lupus Erythematosus, 4th ed. D. J. Wallace and B. H. Hahn, editors. Lea and Febiger, Philadelphia. 157-177.

4. Tsao, B. P., F. M. Ebling, C. Roman, N. Panosian-Sahakian, K. Calame, and B. H. Hahn. 1990. Structural characteristics of the variable regions of immunoglobulin genes encoding a pathogenic autoantibody in murine lupus. J. Clin. Invest. 85:530-540.

5. Ohnishi, K., F. M. Ebling, B. Mitchell, R. R. Singh, B. H. Hahn, and B. P Tsao. 1994. Comparison of pathogenic and nonpathogenic murine antibodies to DNA: antigen binding and structural characteristics. Int. Immunol. 6:817-830.

6. Ando, D. G., E. E. Sercarz, and B. H. Hahn. 1987. Mechanisms of T and $B$ cell collaboration in the in vitro production of anti-DNA antibodies in the NZB/ NZW F1 murine SLE model. J. Immunol. 138:3185-3190.

7. Datta, S. K., H. Patel, and D. Berry. 1987. Induction of cationic shift in IgG anti-DNA autoantibodies: role of $T$ helper cells with classical and novel phenotype in three murine models of lupus nephritis. J. Exp. Med. 165:12521268 .

8. Naiki, M., B.-L. Chiang, D. Cawley, A. Ansari, S. Rozzo, B. L. Kotzin A. Zlotnik, and M. E. Gershwin. 1992. Generation of cloned helper T cell lines for anti-DNA responses in NZB.H-2 ${ }^{\text {bml2 }}$ mice. J. Immunol. 149:4109-4115.

9. Mohan, C., S. Adams, V. Stanik, and S. K. Datta. 1993. Nucleosome: a major immunogen for pathogenic autoantibody-inducing T cells of lupus. $J$. Exp. Med. 177:1367-1381.

10. Weiss, S., and B. Bogen. 1989. B-lymphoma cells process and present their endogenous immunoglobulin to major histocompatibility complex-restricted T cells. Proc. Natl. Acad. Sci. USA. 86:282-286.

11. Yurin, V. L., A. Y. Rudensky, S. M. Mazel, and J. M. Blechman. 1989. Immunoglobulin-specific T-B cell interaction. II. T cell clones recognize the processed form of B cells' own surface immunoglobulin in the context of the major histocompatibility complex class II molecule. Eur. J. Immunol. 19:16851691.

12. Weiss, S., and B. Bogen. 1991. MHC class II-restricted presentation of intracellular antigen. Cell. 64:767-776.

13. Bogen, B., and S. Weiss. 1993. Processing and presentation of idiotypes to MHC-restricted T cells. Int. Rev. Immunol. 10:337-355.

14. Nygard, N. R., D. M. McCarthy, J. Schiffenbauer, and B. D. Schwartz. 1993. Mixed haplotypes and autoimmunity. Immunol. Today. 14:53-56.

15. Hartman, A. B., C. P. Mallett, S. Sheriff, and S. J. Smith-Gill. 1988 Unusual joining sites in the $\mathrm{H}$ and $\mathrm{L}$ chains of an anti-lysozyme antibody. $J$. Immunol. 141:932-936.

16. Maeji, N. J., A. M. Bray, and H. M. Geysen. 1990. Multi-pin synthesis strategy for T cell determinant analysis. J. Immunol. Methods. 134:23-33.

17. Ebling, F. M., B. P. Tsao, R. R. Singh, E. E. Sercarz, and B. H. Hahn 1993. A peptide derived from an autoantibody can stimulate T cells in the (NZB $\times$ NZW) F1 mouse model of systemic lupus erythematosus. Arthritis Rheum. $36: 355-364$

18. Altman, A., A. N. Theofilopoulos, R. Weiner, D. H. Katz, and F. J. Dixon. 1981. Analysis of $T$ cell function in autoimmune murine strains: defects in production of and responsiveness to interleukin 2. J. Exp. Med. 154:791-808.

19. Walker, S. E., and J. E. Hewett. 1984. Responses to T-cell and B-cell mitogens in autoimmune Palmerston North and NZB/NZW mice. Clin. Immunol. Immunopathol. 30:469-478.

20. Ebling, F. and B. H. Hahn. 1980. Restricted subpopulations of DNA antibodies in kidneys of mice with systemic lupus. Arthritis Rheum. 23:392-403.
21. Critchfield, J. M., M. K. Racke, J. C. Zuniga-Pflucker, B. Cannella, C. S. Raine, J. Goverman, and M. J. Lenardo. 1994. T cell deletion in high antigen dose therapy of autoimmune encephalomyelitis. Science (Wash. DC). 263:11391143.

22. Lehmann, P. V., T. Forsthuber, A. Miller, and E. E. Sercarz. 1992. Spreading of T-cell autoimmunity to cryptic determinants of an autoantigen. Nature (Lond.). 358:155-157.

23. Kaufman, D. L., M. Clare-Salzler, J. Tian, T. Forsthuber, G. S. P. Ting, P. Robinson, M. A. Atkinson, E. E. Sercarz, A. J. Tobin, and P. V. Lehmann. 1993. Spontaneous loss of tolerance to glutamic acid decarboxylase in murine insulin-dependent diabetes. Nature (Lond.). 366:69-72.

24. Rudensky, A. Y., P. Preston-Hurlburt, S.-C. Hong, A. Barlow, and C. A. Janeway, Jr. 1991. Sequence analysis of peptides bound to MHC class II molecules. Nature (Lond.). 353:622-627.

25. Chicz, R. M., R. G. Urban, J. C. Gorga, D. A. A. Vignali, W. S. Lane, and J. L. Strominger. 1993. Specificity and promiscuity among naturally processed peptides bound to HLA-DR alleles. J. Exp. Med. 178:27-47.

26. Harris, P. E., A. Maffei, Z. Liu, I. Colovai, F. E. Reed, G. Inghirami, and N. Suciu-Foca. 1993. Naturally processed cytokine-derived peptide bound to HLA-class II molecules. J. Immunol. 151:5975-5983.

27. Chen, J. J., S. V. Kaveri, and H. Kohler. 1992. Cryptic T cell epitopes in polymorphic immunoglobulin regions: evidence for positive repertoire selection during fetal development. Eur. J. Immunol. 22:3077-3083.

28. Singh, R. R., V. Kumar, F. M. Ebling, S. Southwood, A. Sette, E. E Sercarz, and B. H. Hahn. 1995. T cell determinants from autoantibodies to DNA can upregulate autoimmunity in murine systemic lupus erythematosus. J. Exp. Med. 181:2017-2027.

29. Diamond, B., J. B. Katz, E. Paul, C. Aranow, D. Lustgarten, and M. D. Scharff. 1992. The role of somatic mutation in the pathogenic anti-DNA response. Annu. Rev. Immunol. 10:731-757.

30. Ebling, F. M., R. R. Singh, and B. H. Hahn. 1995. In vitro anti-DNA production mediated by Ig derived $\mathrm{T}$ helper determinants: relevance to pathogenesis of lupus. J. Investig. Med. 43:284a. (Abstr.)

31. Bhardwaj, V., V. Kumar, H. M. Geysen, and E. E. Sercarz. 1993. Degenerate recognition of a dissimilar antigenic peptide by myelin basic protein-reactive T cells: implications for thymic education and autoimmunity. J. Immunol. 151:5000-5010.

32. Puccetti, A., T. Koizumi, P. Migliorini, J. Andre-Schwartz, K. J. Barrett, and R. S. Schwartz. 1990. An Ig L chain from a lupus-prone mouse induces autoantibodies in normal mice. J. Exp. Med. 171:1919-1930.

33. Panosian-Sahakian, N., J. L. Klotz, F. Ebling, M. Kronenberg, and B. Hahn. 1989. Diversity of Ig V gene segments found in anti-DNA autoantibodies from a single (NZB $\times$ NZW)F1 mouse. J. Immunol. 142:4500-4506.

34. Tillman, D. M., N.-T. Jou, R. J. Hill, and T. N. Marion. 1992. Both IgM and IgG anti-DNA antibodies are the products of clonally selective B cell stimulation in (NZB $\times$ NZW) $F_{1}$ mice $J$. Exp. Med. 176:761-779.

35. Gangemi, R. M. R., A. K. Singh, and K. J. Barrett. 1993. Independently derived IgG anti-DNA autoantibodies from two lupus-prone mouse strains express a VH gene that is not present in most murine strains. J. Immunol. 151:46604671 .

36. Eilat, D., and R. Fischel. 1991. Recurrent utilization of genetic elements in $\mathrm{V}$ regions of antinucleic acid antibodies from autoimmune mice. J. Immunol. 147:361-368.

37. Gu, H., D. Tarlinton, W. Mueller, K. Rajewsky, and I. Foerster. 1991. Most peripheral B cells in mice are ligand selected. J. Exp. Med. 173:1357-1371. 38. Radic, M. Z., M. A. Mascelli, J. Erikson, H. Shan, M. Shlomchik, and M. Weigert. 1989. Structural patterns in anti-DNA antibodies from MRL/lpr mice. Cold Spring Harbor Symp. Quant. Biol. 54:933-946.

39. Kofler, R., R. Strohal, R. S. Balderas, M. E. Johnson, D. J. Noonan, M. A Duchosal, F. J. Dixon, and A. N. Theofilopoulos. 1988. Immunoglobulin $\kappa$ light chain variable region gene complex organization and immunoglobulin genes encoding anti-DNA autoantibodies in lupus mice. J. Clin. Invest. 82:852-860. 